\title{
Genomic and Phenotypic Alterations of the Neuronal-Like Cells Derived from Human Embryonal Carcinoma Stem Cells (NT2) Caused by Exposure to Organophosphorus Compounds Paraoxon and Mipafox
}

David Pamies ${ }^{1,2,3, *}$, Miguel A. Sogorb ${ }^{1}$, Marco Fabbri ${ }^{2,4}$, Laura Gribaldo ${ }^{2}$, Angelo Collotta ${ }^{2}$, Bibiana Scelfo $^{2}$, Eugenio Vilanova ${ }^{1}$, Georgina Harris ${ }^{2,3}$ and Anna Bal-Price ${ }^{2}$

1 Bioengineering Institute, Miguel Hernández University, Elche 03202, Alicante, Spain;

E-Mails: msogorb@umh.es (M.A.S.); evilanova@umh.es (E.V.)

2 Institute for Health and Consumer Protection, European Commission Joint Research Centre, Ispra, Varese 21027, Italy; E-Mails: marco.fabbri@gmail.com (M.F.);

laura.gribaldo@ec.europa.eu (L.G.); angelo.collotta@jrc.ec.europa.eu (A.C.);

bibiana.scelfo@gmail.com (B.S.); georgina.hlopez@gmail.com (G.H.); anna.price@jrc.ec.europa.eu (A.B.-P.)

3 Bloomberg School of Public Health, Johns Hopkins University, CAAT, Baltimore, MD 21205, USA

4 Department of Experimental and Clinical Medicine, University of Insubria, Varese 21100, Italy

* Author to whom correspondence should be addressed; E-Mail: dpamies@jhsph.edu; Tel.: +1-410-614-4990; Fax: +1-470-614-2871.

Received: 14 October 2013; in revised form: 8 December 2013 / Accepted: 17 December 2013 / Published: 9 January 2014

Abstract: Historically, only few chemicals have been identified as neurodevelopmental
toxicants, however, concern remains, and has recently increased, based upon the
association between chemical exposures and increased developmental disorders.
Diminution in motor speed and latency has been reported in preschool children from
agricultural communities. Organophosphorus compounds (OPs) are pesticides due to their
acute insecticidal effects mediated by the inhibition of acetylcholinesterase, although other
esterases as neuropathy target esterase (NTE) can also be inhibited. Other neurological and
neurodevelopmental toxic effects with unknown targets have been reported after chronic
exposure to OPs in vivo. We studied the initial stages of retinoic acid acid-triggered
differentiation of pluripotent cells towards neural progenitors derived from human
embryonal carcinoma stem cells to determine if neuropathic OP, mipafox, and 
non-neuropathic OP, paraoxon, are able to alter differentiation of neural precursor cells in vitro. Exposure to $1 \mu \mathrm{M}$ paraoxon (non-cytotoxic concentrations) altered the expression of different genes involved in signaling pathways related to chromatin assembly and nucleosome integrity. Conversely, exposure to $5 \mu \mathrm{M}$ mipafox, a known inhibitor of NTE activity, showed no significant changes on gene expression. We conclude that $1 \mu \mathrm{M}$ paraoxon could affect the initial stage of in vitro neurodifferentiation possibly due to a teratogenic effect, while the absence of transcriptional alterations by mipafox exposure did not allow us to conclude a possible effect on neurodifferentiation pathways at the tested concentration.

Keywords: neurodifferentiation; neurodevelopmental toxicity; NT2; organophosphorus pesticides; NTE; human embryonal carcinoma stem cells

Abbreviations and organophosphorus compounds common names: $\mathrm{AChE}=$ Acetylcholinesterase; DAPI = 4-6-diamidino-2-phenylindole; FBS = foetal bovine serum; FGFR1 = Fibroblasts growth factor receptor 1; GFAP $=$ Glial fibrillary acidic protein; NT2 $=$ human-derived NTera2/D1 cells; MAP2 $=$ Microtubule-associated protein 2; Mipafox $=N, N$-diisopropyl diamidophosphorofluoridate; MTT = 3-(4,5-dimethylthiazol-2-yl)-2,5-diphenyltetrazolium bromide; NCBI = National Center for Biotechnology Information; NTE = neuropathy target esterase; OPs = organophosphorus compounds; Paraoxon $=O, O^{\prime}$-diethyl $p$-nitrophenyl phosphate; PBS = phosphate buffered saline; $\mathrm{PV}=$ phenyl valerate; RA = retinoic acid; SEM = standard error of the mean; YAP1 = Yes-associated protein 1.

\section{Introduction}

Organophosphorus compounds (OPs) have been used worldwide as pesticides for insect control. In Europe alone, OP insecticide production was close to 31,000 tons in 2010 [1]. The American Association of Poison Control Centers reported almost 4000 exposures to OPs and four exposure-related fatalities in 2010 [2]. Many OPs target the nervous system of insect pests. Because of the similarity of neurochemical processes, these compounds are also likely to be neurotoxic to human brain, especially to the developing nervous system which is inherently much more vulnerable to injury caused by toxic agents than the brain of adults [3-5]. Indeed, there are evidences that pesticides reduce motor activity, latency and cause visuospatial deficits after high exposure [6,7]. The main mechanism of action of OPs is based on irreversible enzyme inactivation caused by the phosphorylation of the active centre of esterases located in the neurons of the central and peripheral nervous systems [8]. The inhibition of esterases can cause two main types of poisoning effects. The insecticidal effects of OPs are specifically due to acetylcholinesterase (AChE) inhibition, which is essential for the transmission of nervous signals in target (insects) and non-target (e.g., humans and other mammals) species [8]. However, another syndrome has been described after exposure to some OPs, the so-called organophosphorus-induced delayed polyneuropathy. This is a paralyzing syndrome characterized by the degeneration of nerve axons, which is clinically detectable 14 to 16 days post-exposure [9]. 
Conversely, this delayed neuropathy is triggered by the phosphorylation and further chemical modification of an esterase (other than AChE) called Neuropathy Target Esterase (NTE) [9].

In addition, low-level chronic exposures, which usually take place in occupational environments, can cause other neurotoxic effects. Incidences of neurological and neurodegenerative diseases have been reported in epidemiologic studies performed with pesticide spreaders, greenhouse workers, agricultural workers and farmers occupationally exposed to pesticides (including OPs) [10-12]. OPs also might be developmental toxicants due to the inhibition of esterases during pregnancy, oxidative stress or endocrine disruption [13]. It has also been suggested that the neurodevelopmental toxicity of OPs may be due to direct interference with the morphogenic activity that AChE normally displays during neurodevelopment $[14,15]$, which might alter neural connectivity, induce long-lasting changes in spatial learning and memory formation [16], or alter the expression of genes involved in nervous system development [17,18], as it is specifically described for the OP chlorpyrifos. Epidemiologic and laboratory animal studies suggest that pesticides (OPs, carbamates, pyrethroids and others) can cause developmental neurotoxicity [3]. In addition, an anthropological study of children aged 4-5 years in Mexico showed that children highly-exposed to pesticides demonstrated decreases in stamina, gross and fine eye-hand coordination, perturbation in short term memory, and the ability to draw a picture of a person [19].

Neurotoxic effects depend on the developmental window in which the exposure takes place and can be particularly severe in early stages, when complex cellular-molecular processes of neural progenitor cell commitment, cell proliferation, migration and differentiation take place $[4,5,20]$. Damage to any of these processes can cause a variety of adverse health effects, such as mental retardation, altered behavior and other neurodevelopmental diseases [21].

Human-derived NTera2/D1 (NT2) cells have the capacity to differentiate into fully mature neuronal and astrocyte-like cells [22]. During this process, the neuron-like cells derived from NT2 neural progenitor cells could serve as a valuable model for developmental neurotoxicity studies since various cell differentiation stages can be followed in these cultures [23,24].

The main goal of this study is to determine whether exposure to model OPs during retinoic acid (RA)-induced differentiation of pluripotent cells is able to affect the neural commitment of progenitor cells followed by the alterations in the initial process of neuronal differentiation. Indeed, this very early exposure of neural progenitor cells to environmental toxicants seems to be one of the most sensitive time intervals during development causing neurotoxicity [25,26]. Microarray technology has been used to screen the developmental neurotoxic effects induced by OPs [27]. We studied alterations in the expression of the whole human genome in RA-induced differentiation of pluripotent cells towards neural progenitors from NT2 cells by exposure to non-neuropathic OP paraoxon (the physiologically active derivative of the insecticide parathion) or neuropathic OP mipafox. Non-cytotoxic concentrations of paraoxon affected the expression of several genes related mainly to DNA and nucleosome integrity. In contrast, mipafox exposure showed no changes in gene expression. 


\section{Results}

\subsection{Cell Viability after Exposure to OPs}

In the dose response assessment of paraoxon and mipafox, NT2 cells were exposed for 4, 10 and 15 days to several paraoxon and mipafox concentrations ranging between 0.5 and $300 \mu \mathrm{M}$. After 4 days exposure to paraoxon, only concentrations higher than $200 \mu \mathrm{M}$ reduced cell viability $(p<0.05)$ (Figure 1), while none of the tested mipafox concentrations had any effect as evaluated by MTT assay. However, after 10 days of mipafox exposure to the concentrations higher than $70 \mu \mathrm{M}$, the cells showed significant loss in cell viability (Figure 1). After longer time of exposure, 15 days, paraoxon and mipafox significantly reduced cell viability $(p<0.05)$ at concentrations higher than $100 \mu \mathrm{M}$ and $200 \mu \mathrm{M}$ respectively, while $1 \mu \mathrm{M}$ paraoxon and $5 \mu \mathrm{M}$ mipafox did not alter viability (Figure 2). Based on these results, $1 \mu \mathrm{M}$ paraoxon and $5 \mu \mathrm{M}$ mipafox were selected for transcriptomics studies as non-cytotoxic concentrations.

\subsection{Effect of Paraoxon and Mipafox on NTE Activity}

Non-neuropathic OP paraoxon did not inhibit NTE after 4, 10 or 15 days of exposure (Figure 3). Conversely, neuropathic OP mipafox caused an extensive inhibition of NTE (Figure 3). This inhibition was significant after 4 days of exposure to $5 \mu \mathrm{M}$ mipafox, and reached approximately $8 \%$ of control activity after exposure to $300 \mu \mathrm{M}$ (Figure 3). Similar results were observed after 10 and 15 days of exposure.

Figure 1. NT2 neural progenitor cells. (A) Phase contrast images showing NT2 neural progenitor cells; (B) Expression of NPC (neural progenitor cells) marker, nestin, co-stained with 4',6-diamidino-2-phenylindole (DAPI) show $100 \%$ positive nestin cells. Bars correspond to $500 \mu \mathrm{m}$.

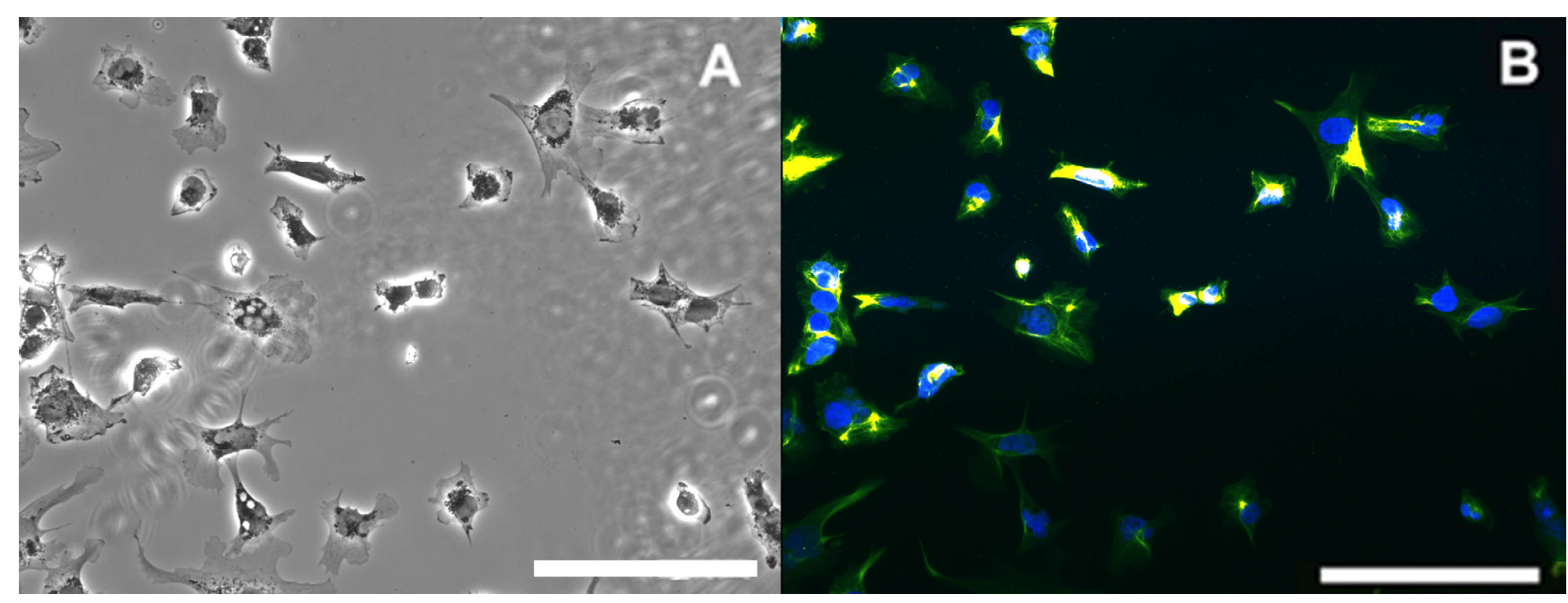


Figure 2. Effect of paraoxon and mipafox on cell viability of NT2 cells during the first stage of neurodifferentiation measured by MTT assay. Cells were exposed to $0.5,1,5,10$, $25,40,70,100,150,200$ and $300 \mu \mathrm{M}$ of either paraoxon $(\bullet)$ or mipafox $(\boldsymbol{\Delta})$ for 4 days (A); 10 days (B); and 15 days (C). Data represent mean \pm SEM of the four independent experiments with 16 independent technical replicates for each experimental condition run. (* statistically different from the controls for $p<0.05$ in both paraoxon and mipafox by Dunnett's test).

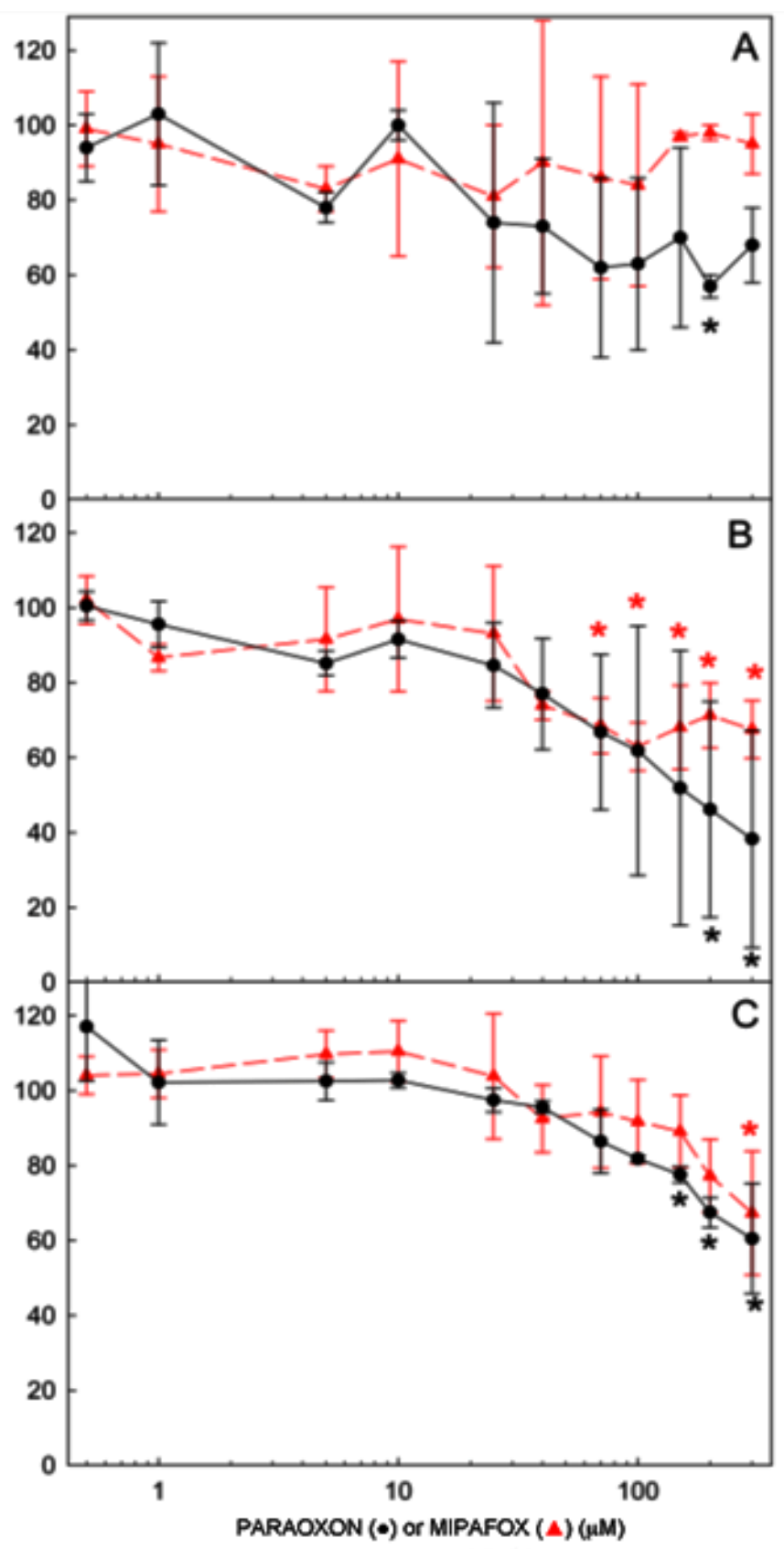


Figure 3. Changes in NTE activity of the NT2 cells exposed to paraoxon or mipafox during the neurodifferentiation process. Cells were exposed to $0.5,1,5,10,25,40,70,100$, 150,200 and $300 \mu \mathrm{M}$ of either paraoxon $(\bullet)$ or mipafox $(\mathbf{\Delta})$ for 4 days $(\mathbf{A})$; 10 days $(\mathbf{B})$; and 15 days (C). NTE activity is expressed as the percentage of activity determined in the time-matched control (non-exposed) cultures. Data represent mean \pm SEM of three independent experiments with 8 technical replicates for each experimental condition. (* statistically different from the controls for $p<0.05$ with a Dunnett's test).

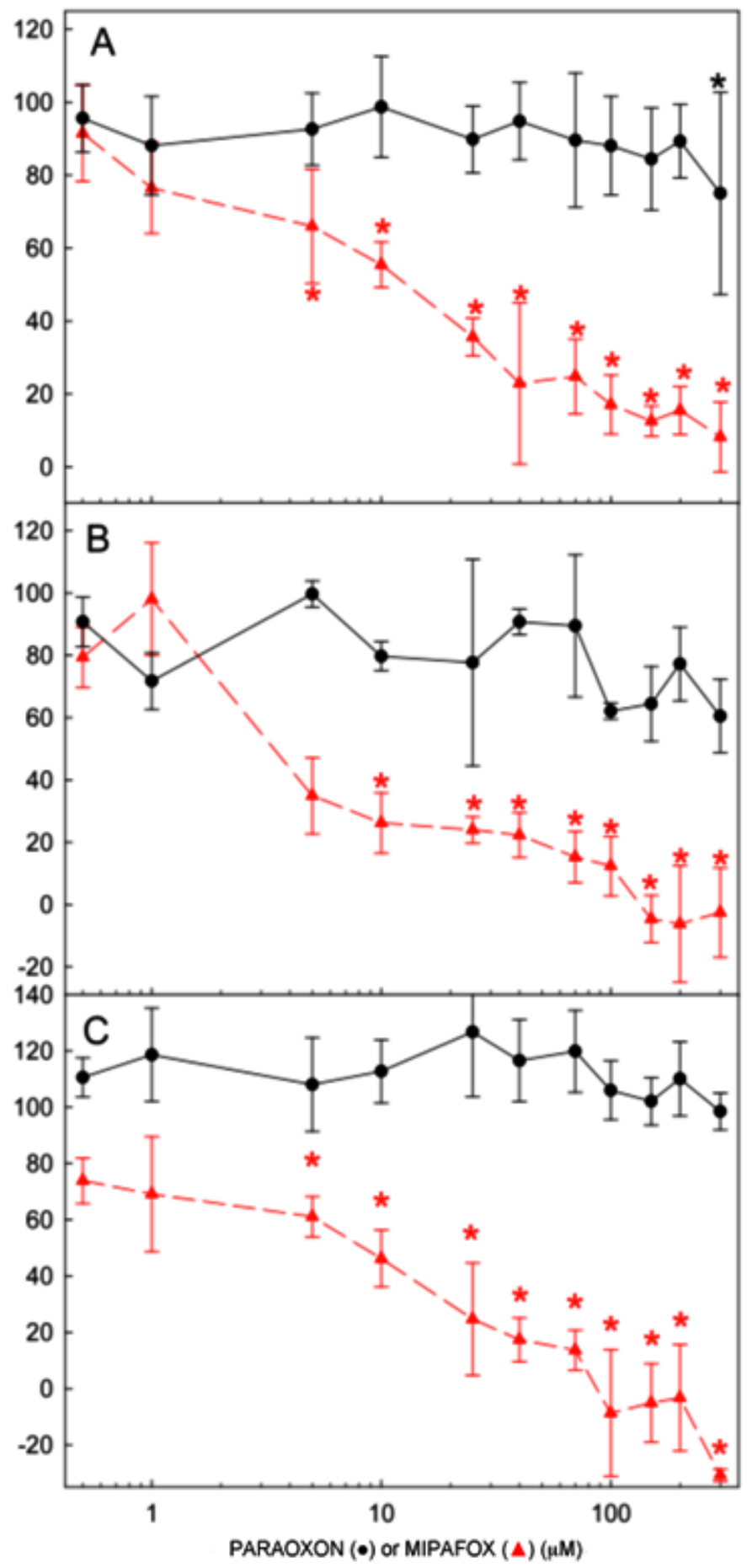




\subsection{Microarray Analysis after 4-Day Exposure}

The mRNA expression across the whole human genome was evaluated in NT2 cells during the initial stage of RA-induced differentiation of pluripotent cells towards the neural committed progenitor cells after 4 days of exposure to $1 \mu \mathrm{M}$ paraoxon or $5 \mu \mathrm{M}$ mipafox (both are non-cytotoxic concentrations) using microarray analysis. Paraoxon caused a statistically significant alteration in the expression of 137 genes, while exposure to mipafox altered the expression of a single gene (Figure 4). No overlapping was noted between the genes altered by paraoxon exposure and the single gene altered by mipafox exposure (Figure 4). The one gene modified by mipafox treatment was a long non-coding RNA, a non-protein coding transcript related with a transcription function.

Figure 4. Venn diagram of the genes with altered expressions after exposure to paraoxon and mipafox. Cells were exposed to $1 \mu \mathrm{M}$ paraoxon or $5 \mu \mathrm{M}$ mipafox for 4 days. Afterwards, the whole human genome expression was recorded using microarrays, as described in Section 4.6. Each compartment represents the number of genes with a statistically (at least corrected $p<0.05$ ) altered expression found in each condition. $\downarrow$ down-regulated genes, $\uparrow$ up-regulated genes.

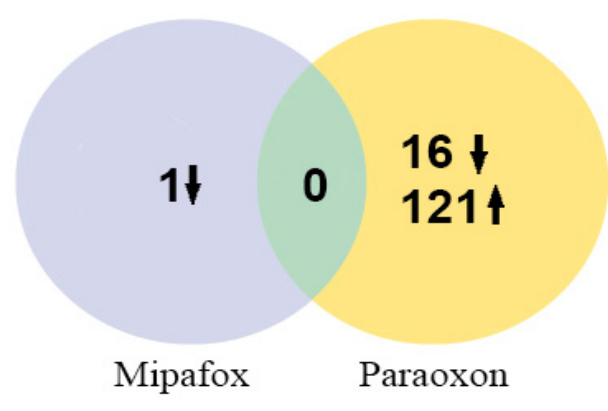

The data obtained from gene expression studies was further analyzed with the DAVID software using the Gene Ontology database separated into three parts: biological process, molecular function and cellular components [28]. For analysis purposes, only those genes with a fold change higher than 2 or lower than 0.5 and with a corrected $p$-value lower than 0.05 were considered. The highest enrichment score was found for a cluster of genes related to nucleosome and chromatin assembly (Table 1). An independent analysis of the up-regulated and down-regulated genes showed that these modifications were attributable to down-regulated genes (raw data in Supplementary Materials 2). Table 2 shows the genes which mRNA levels altered up-regulated and down-regulated after paraoxon exposure. The function of most of these genes is related to chromatin assembly and chromatin regulation (HIST1H2AB, HIST1H4E, CBX3), apoptosis (FKSG2 and UBE2Z) or cell-cell signaling and differentiation (FGFR1, YAP1, SRGAP2P2). 
Table 1. Gene set enrichment analysis. Cells were exposed to $1 \mu \mathrm{M}$ paraoxon for 4 days in RA-induced differentiation medium. All genes with statistically $(p<0.05)$ altered expressions and a fold change higher than 2 or lower than 0.5 were uploaded for further analysis in the DAVID bioinformatics (Nature. Available online: http://www.nature.com/nprot/ journal/v4/n1/abs/nprot.2008.211.html (accessed on 26 December 2013). * $p$-value $<0.05$.

\begin{tabular}{lcc}
\hline \multicolumn{1}{c}{ Function } & $\begin{array}{c}\text { Number of genes associated } \\
\text { with processes altered }\end{array}$ & $\begin{array}{c}\text { Corrected } \\
\boldsymbol{p} \text {-value }\end{array}$ \\
\hline Cluster Enrichment score $=\mathbf{1 . 7}$ & 4 & $0.001 *$ \\
Chromatin assembly & 3 & $0.010 *$ \\
Nucleosome assembly & 3 & $0.011 *$ \\
Protein-DNA complex assembly & 3 & $0.012 *$ \\
Nucleosome organization & 4 & $0.018 *$ \\
Cellular macromolecular complex assembly & 3 & $0.018 *$ \\
DNA package & 4 & $0.024 *$ \\
Cellular macromolecular complex subunit organization & 4 & $0.028 *$ \\
Chromatin organization & 4 & $0.053 *$ \\
Chromosome organization & & \\
\hline Cluster Enrichment score $=\mathbf{1 . 3 3}$ & 6 & $0.0019 *$ \\
Enzyme binding & 5 & $0.036 *$ \\
Cell death & 5 & $0.037 *$ \\
Death & 3 & 0.29 \\
Apoptosis & 3 & 0.3 \\
Programmed cell death & & \\
\hline Cluster Enrichment score $=\mathbf{1 . 0 4}$ & 3 & $0.051 *$ \\
Regulation of cell size & 3 & 0.083 \\
Regulation of cellular component size & 3 & 0.18 \\
Neuro differentiation & & \\
\hline
\end{tabular}

\subsection{Effect of Paraoxon and Mipafox on the Morphology of NT2-Derived Neurons}

The morphology of NT2 cells differentiating towards neuronal-like phenotype for 13 days (in the presence of RA) were stained positively against $\beta$-Tubulin III (neuronal specific marker) and their morphology was analyzed using the imaging platform Cellomics ArrayScan vTi (Thermo Scientific Cellomics ${ }^{\circledR}$, Pittsburgh, PA, USA), as described in Section 4.6. Paraoxon caused a statistically significant increase $(11.4 \%$ regarding the control, $p<0.05)$ in the total number of differentiated neuronal-like cells (cell bodies with more than 3 processes or with processes whose total length was longer than $6.5 \mu \mathrm{m}$ ) present in cultures, while no differences in this parameter were recorded between the control and mipafox-exposed cultures (Figure 5A). Likewise, the total number of branch points in differentiating cells was higher $(258 \%$ of control, $p<0.05)$ in the cultures that were differentiating in the presence of paraoxon than in the control cultures, while the presence of mipafox did not alter the number of branch points (Figure 5B). However, the cultures exposed to both paraoxon or mipafox displayed no significant differences in terms of total length of neurites per well (Figure 5C) and total number of dense (non-apoptotic) nuclei per well (data not shown). 
Table 2. Genes altered in NT2 cells induced by paraoxon during the initial stage of RA-induced differentiation of pluripotent cells towards the neural committed progenitor cells. Cells were exposed to $1 \mu \mathrm{M}$ paraoxon for 4 days in RA-induced differentiation. Data represent the genes linked to altered mRNA levels compared to control (non-exposed) cultures as identified according to the National Center for Biotechnology Information (NCBI) database.

\begin{tabular}{|c|c|c|c|}
\hline Gene & Name & NCBI entry & FC real \\
\hline HISTIH4E & histone cluster $1, \mathrm{H} 4 \mathrm{e}$ & 8367 & -1.69 \\
\hline LUZP6 & leucine zipper protein 6 & 767558 & -1.57 \\
\hline LOC400804 & hypothetical LOC400804 & 400804 & -1.24 \\
\hline$H I S T 1 H 2 A B$ & histone cluster 1, H2ab & 8335 & -1.23 \\
\hline C14orf162 & chromosome 14 open reading frame 162 & 56936 & -1.19 \\
\hline YAP1 & Yes-associated protein 1 & 10413 & -1.15 \\
\hline FGFR1 & fibroblast growth factor receptor 1 & 2260 & -1.05 \\
\hline AKAP12 & A kinase (PRKA) anchor protein 12 & 9590 & -1.03 \\
\hline$U B E 2 Z$ & ubiquitin-conjugating enzyme E2Z & 65264 & -1.01 \\
\hline$S R G A P 2 P 2$ & SLIT-ROBO Rho GTPase activating protein 2 pseudogene 2 & 647135 & -1.01 \\
\hline AXIN2 & axin 2 & 8313 & -1.00 \\
\hline LOC646214 & p21-activated kinase 2 pseudogene & 646214 & 1.00 \\
\hline LOC100130654 & hypothetical protein LOC100130654 & 100130654 & 1.00 \\
\hline CCR6 & chemokine (C-C motif) receptor 6 & 1235 & 1.01 \\
\hline C14orf135 & chromosome 14 open reading frame 135 & 64430 & 1.01 \\
\hline KIRREL2 & kin of IRRE like 2 (Drosophila) & 84063 & 1.01 \\
\hline$C 2 \operatorname{orf} 27 A$ & chromosome 2 open reading frame $27 \mathrm{~A}$ & 29798 & 1.02 \\
\hline$B M P 8 B$ & bone morphogenetic protein $8 \mathrm{~b}$ & 656 & 1.03 \\
\hline$R N F 113 B$ & ring finger protein $113 \mathrm{~B}$ & 140432 & 1.05 \\
\hline$G C L M$ & glutamate-cysteine ligase, modifier subunit & 2730 & 1.06 \\
\hline TTC16 & tetratricopeptide repeat domain 16 & 158248 & 1.07 \\
\hline PARP4 & poly (ADP-ribose) polymerase family, member 4 & 143 & 1.07 \\
\hline LOC100134868 & hypothetical LOC100134868 & 100134868 & 1.07 \\
\hline SCD5 & stearoyl-CoA desaturase 5 & 79966 & 1.08 \\
\hline$P T K 2 B$ & PTK2B protein tyrosine kinase 2 beta & 2185 & 1.08 \\
\hline LAT2 & linker for activation of $\mathrm{T}$ cells family, member 2 & 7462 & 1.10 \\
\hline RPL13AP17 & ribosomal protein L13a pseudogene 17 & 399670 & 1.10 \\
\hline$A C B D 5$ & acyl-CoA binding domain containing 5 & 91452 & 1.16 \\
\hline Clorf152 & profilin 1 pseudogene & 767846 & 1.17 \\
\hline$Y Y 2$ & YY2 transcription factor & 404281 & 1.18 \\
\hline LOC100133791 & hypothetical protein LOC100133791 & 100133791 & 1.21 \\
\hline LOC100233209 & hypothetical LOC100233209 & 100233209 & 1.24 \\
\hline ILDR1 & immunoglobulin-like domain containing receptor 1 & 286676 & 1.26 \\
\hline LOC648740 & actin, beta pseudogene & 648740 & 1.28 \\
\hline SET & SET nuclear oncogene & 6418 & 1.29 \\
\hline LOC100131581 & hypothetical LOC100131581 & 100131581 & 1.29 \\
\hline \multirow[t]{2}{*}{ CXCL5 } & chemokine (C-X-C motif) ligand 5 & 6374 & 1.30 \\
\hline & nascent-polypeptide-associated complex alpha polypeptide & & \\
\hline$N A C A P 1$ & pseudogene 1 & 83955 & 1.30 \\
\hline
\end{tabular}


Table 2. Cont.

\begin{tabular}{llcc}
\hline Gene & Name & NCBI entry & FC real \\
\hline KRTAP10-9 & keratin associated protein 10-9 & 386676 & 1.33 \\
CBX3 & chromobox homolog 3 & 11335 & 1.37 \\
SNRPD2P2 & small nuclear ribonucleoprotein D2 pseudogene 2 & 645339 & 1.39 \\
SGSM2 & small G protein signaling modulator 2 & 9905 & 1.42 \\
ANXA2 & annexin A2 & 302 & 1.59 \\
REREP3 & arginine-glutamic acid dipeptide (RE) repeats pseudogene 3 & 646396 & 1.78 \\
$F K S G 2$ & tumor protein, translationally-controlled 1 pseudogene & 59347 & 1.80 \\
$T X N D C 17$ & thioredoxin domain containing 17 & 84817 & 1.94 \\
\hline
\end{tabular}

Figure 5. Effects of paraoxon and mipafox on the neural differentiation. During the initial process of neural differentiation NT2 cells were seeded on 96-well plates and exposed to $1 \mu \mathrm{M}$ paraoxon or $5 \mu \mathrm{M}$ mipafox for 13 days. Using the Cellomics ArrayScan device the following morphological parameters of the cells positively stained against $\beta$-Tubulin III were quantified: differentiating neuronal-like cells (cells with more than 3 neurites or with a neurite total length longer than $6.5 \mu \mathrm{m})(\mathbf{A})$; number of branch points $(\mathbf{B})$ and length of neurites $(\mathbf{C})$; Each Figure shows the results obtained together with a representative picture, randomly selected among those employed for quantification. Each experimental condition was assayed in 16 wells ( 6 different pictures per well). Plots represent mean \pm SEM of all records performed per each experimental condition. * statistically different from the controls for $p<0.05$ with Dunnett's test. Pictures show morphology and staining of analyzed cultures (white bars represent $500 \mu \mathrm{m}$ ); (D) Nuclear staining with DAPI; (E) Staining of neuronal bodies with â-tubulin III; (F) Double staining (green for $\beta$-tubulin III and blue for DAPI); and (G) The same picture analyzed Cellomics ArrayScan device. Note in $(\mathbf{G})$ blue cellular outlines for neurons with neurites meeting the above defined threshold, while red outlines remark neuronal bodies that were not quantified because they did not meet the set threshold. See also in (G) neurites (green) and nuclei (blue) that were not outlined for quantification because they were not considered as neurons.
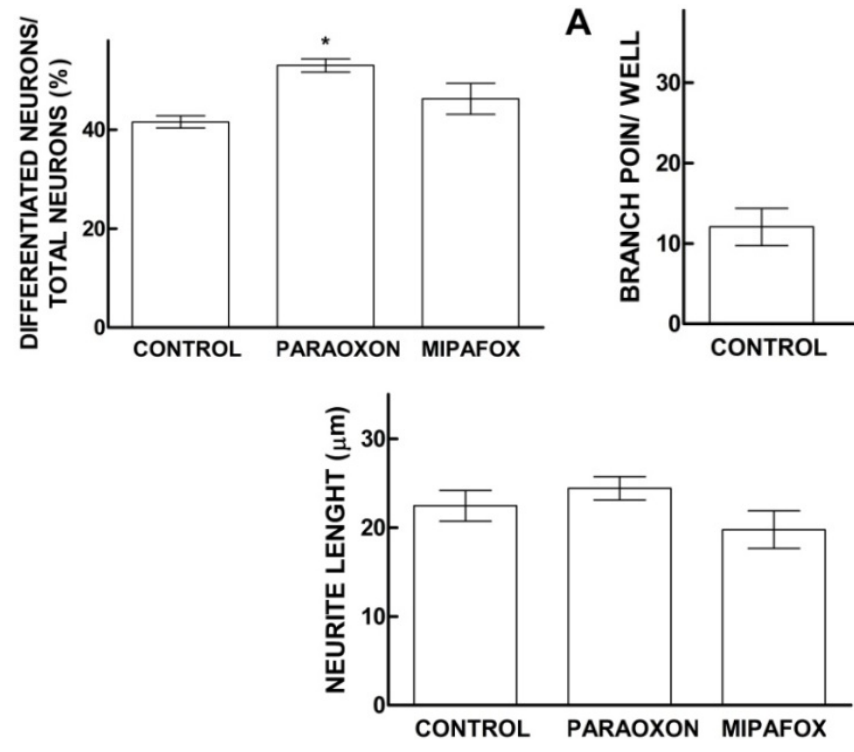

A

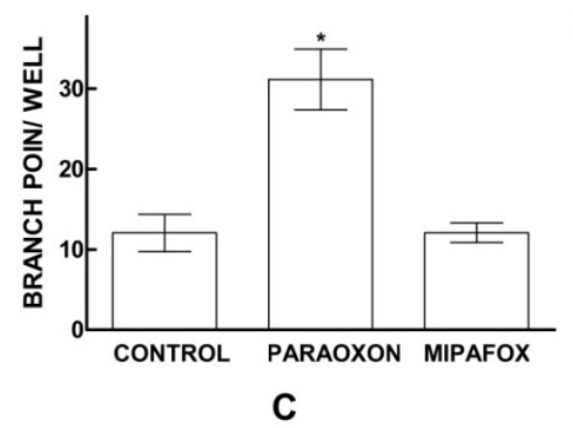

B 
Figure 5. Cont.

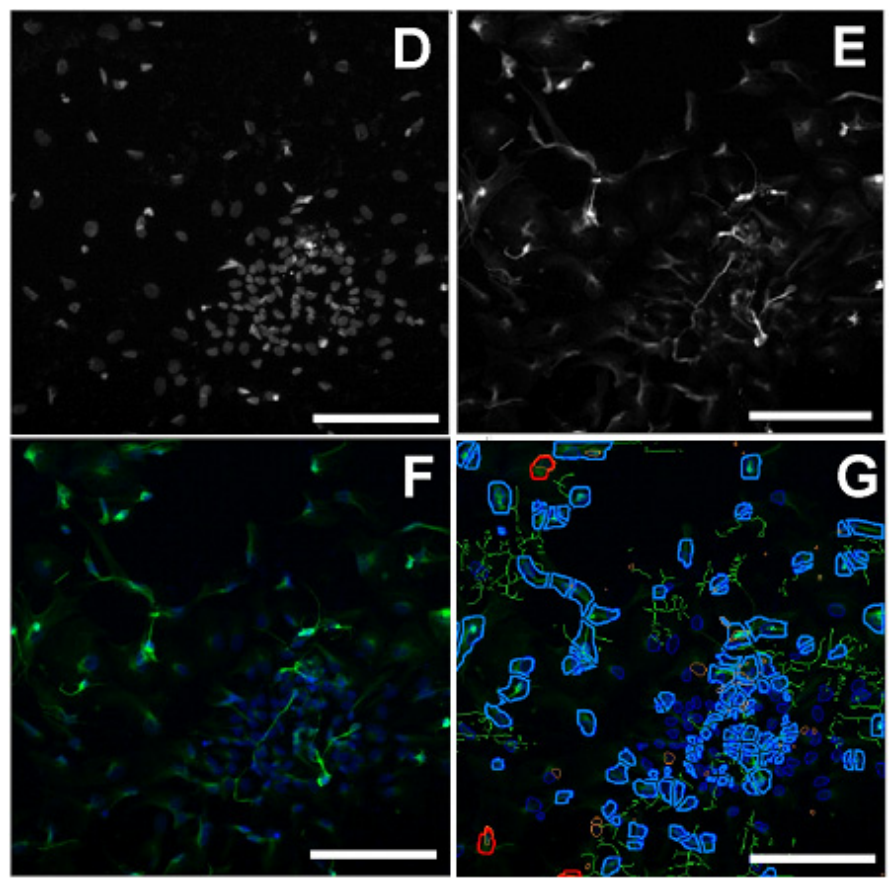

\section{Discussion}

The main mechanism for acute toxic effects of OPs is the inhibition of AChE in the nervous system. Nevertheless, other deleterious effects have been reported for these pesticides, such as inhibition of other esterases (i.e., NTE), damage to DNA and RNA synthesis [29], dysregulation of signal transduction pathways [30], oxidative stress [30], astroglial proliferation [31], embryogenesis dysfunction [32,33].

In this work, we used a neuronal progenitor cells of undifferentiated NT2 cells in the presence of RA, to study the effects of mipafox (a neuropathic OP capable of inhibiting NTE and inducer of the so-called organophosphorus induced polyneuropathy) [34] and paraoxon (a non-neuropathic OP that is not able to inhibit NTE) $[35,36]$ on the initial stages of neuronal differentiation process under in vitro conditions. This early exposure of neural progenitor cells to environmental chemicals seems to be one of the most sensitive time intervals of exposure in the context of developmental neurotoxicity. Indeed, it has been shown that NT2 derived neural precursors were already affected by non-cytotoxic concentrations of methyl mercury [25,37]. In contrast these concentrations did not affect the markers of more mature cells, indicating that the early window of exposure is more sensitive than later stages of neuronal differentiation. A similar conclusion was obtained based on the exposure of a human neural precursor cells derived from umbilical cord blood (HUCB-NSC) to various developmental neurotoxic compounds, including methyl mercury chloride. Less differentiated cells of HUCB-NSC were more sensitive to neurotoxicants [25] than the cells at the later stage of neuronal differentiation. Compounds that can affect the very initial stage of neural precursor's commitment are potential developmental neurotoxicants and this early exposure can be critical for changes observed in the neuronal/glial ratio and/or neuronal/glial cell morphology and function. NT2 are capable to differentiate in both neuronal and glial cells.

In this study mRNA levels have been found to be modified based on microarray analysis of the cells exposed to paraoxon during 4 days. Preliminary studies have shown that after 13 days of exposure to 
paraoxon, the cells differentiating towards neuronal phenotype (stained positively against $\beta$-Tubulin III) have a tendency towards increased number of branch points and higher number of differentiated neuronal-like cells (Figure 5). However, further studies are needed to confirm this. The results obtained from mRNA expression modification point towards the fact that paraoxon could have an effect on early stages of neural precursor commitment and the initial differentiation into neuronal-like cells.

\subsection{Effects of Mipafox during NT2 Neurodifferentiation}

Previous studies with mipafox have reported that different NTE inhibiting neuropathic OPs caused reduced neurites length in the SH-SY5Y human neuroblastoma [38], N2a mouse neuroblastoma [39], C6 rat glioma [40], sympathetic neurons deriving from superior cervical ganglia [41], chick embryo dorsal root ganglia [42] or PC12 cells [43]. Moreover, Henschler et al. [44] reported that 26 different neuropathic OPs reduced the length of the neurites-like processes induced by dibutyryl cAMP in the N18 mouse brain neuroblastoma and processes of the C6 rat brain glioma cells while eight non-neuropathic OPs did not. However, the studies in which EB2.2 mouse embryonic stem cells with the knocked-out NTE encoding gene were used; a delay in the onset of neurite outgrowth (but no effect on their total length) was observed [45]. The above-reported differences can be explained on the basis of different cellular models, different concentrations applied, time of exposure and on mechanisms of reduction of NTE activity (chemical inhibition of the protein with mipafox or other neuopathic OPs in SH-SY5Y, C6, PC12, N18 cells and chick embryo dorsal root ganglia or genetic silencing in EB2.2 cells and D3 mouse embryonic stem cells). NT2 is a human embryonal carcinoma cell line classified as stem cells that can differentiate into post-mitotic neurons under RA exposure [22], while the other cellular systems used for studying alterations in neurites outgrowth are either somatic stem cells or adult cells. Therefore, it can be expected that these cells were at different stages of differentiation processes during mipafox exposure, which might determine the response of differentiating cells to the insult of the OP.

In our studies no genetic modifications due to mipafox exposure have been reported. However, interference RNA for Pnpla6 (NTE encoding gene) has shown different genetic modifications in D3 mouse embryonic stem cells during the differentiation of embryonic bodies [32]. A reduction of NTE enzymatic activity in NT2 cells did not produce any modifications in gene expression. Again, these differences could be due to the different cellular models used, different concentrations applied and time of exposure as well as different mechanisms of reduction of NTE activity (genetic repression of Pnpla6 or NTE enzymatic activity inhibition).

\subsection{Effects of Paraoxon during Initial Stage of NT2 Neurodifferentiation}

Parathion and, in consequence, the physiologically active derivative paraoxon have shown to induce developmental neurotoxicity effects in humans [46]. Paraoxon exposure caused changes in mRNA levels as determined by microarray analysis already after 4 days of neuronal differentiation triggered by RA. These findings may support our preliminary results where increased neuronal differentiation (number of total differentiating cells towards neuronal phenotype and number of branch points (Figure 5) after exposure to paraoxon was observed. Such effect could change the networking between the mature neurons that can be obtained in this cell model. Indeed, based on our early studies [47] 
these cells have capacity to differentiate into fully mature neurons following the protocol described by Pleasure [48].

The pathway analysis performed with the DAVID bioinformatics tool for the 137 genes with altered expression strongly suggests an association with the pathways related to DNA integrity and to nucleosome and chromatin assembly (Table 1). The analysis of the altered mRNA levels of different genes (Table 2) reveals that they belong to different families, such as $\mathrm{CBX} 3$, related to chromatin regulation [49], or HIST1H4E and HIST1H2AB, related with nucleosome assembly [50], or YAP1, related with the regulation of different processes in development [51]. These results are consistent with other reports where DNA damage in the lymphocytes of workers occupationally exposed to OPs was detected [52-54].

The exposure to paraoxon down-regulates also the mRNA levels of growth factor receptor 1 (FGFR1) that is involved in cellular proliferation. It was demonstrated, for example, that FGFR1-deficient mice develop an abnormal olfactory bulb due to failure in the decrease of cell proliferation, indicating that FGF signaling is required to inhibit proliferation at the anterior tip of the forebrain [55]. Yes-associated protein 1 (YAP1) is a transcriptional co-activator that controls cell proliferation and differentiation in a variety of tissues during development. An increase in differentiation in mouse retina cells after silencing has been demonstrated [56]. Both mRNA levels of (FGFR1 and YAP1) were down-regulated after 4 days of exposure to paraoxon (Table 2), which could support the increase in the number of differentiated neurons found 13 days after neurodifferentiation (Figure 5). Additionally, mRNA levels of other genes such as FGFR1, SGSM2, SET, SCD5 related to nervous system development have been modified. However, paraoxon and paraoxon-methyl have been also shown to produce teratogenicity and genotoxicity in different models [57-59]. Moreover, gene set enrichment analysis has shown mRNA levels modify of genes related with apoptosis and cell size regulation (Table 1) function. Taking these results into consideration, it is possible that the effects observed in our study may be due to teratogenicity induced by paraoxon. Indeed, microarrays analysis have shown impaired chromosome packaging and organization (Table 1) that could produce chromosome aberration, normally linked with teratogenicity effects.

\section{Material and Methods}

\subsection{Chemicals}

Paraoxon (O,O'-diethyl $p$-nitrophenyl phosphate) was obtained from Sigma-Aldrich S.A. (Madrid, Spain) and mipafox ( $N, N$-diisopropyl diamidophosphorofluoridate) was purchased from Lark Enterprise (Webster, MA, USA).

\subsection{NT2 Cell Differentiation into Neuronal-like Cells}

The NTERA-2 cl. D1 (NT2) cell line derived from human teratocarcinoma, was purchased from the American Type Culture Collection (Rockville, MD, USA). Two different culture media (for proliferation of neural progenitor cells (NPC) and for neuronal differentiation) were used according to the protocol described by Pleasure et al. [48]. Initially, the neural progenitor NT2 cells (Figure 1) were cultured in uncoated $75-\mathrm{cm}^{2}$ flasks (Nunc, New York, NY, USA) at a density of $4 \times 10^{4} \mathrm{cells} / \mathrm{cm}^{2}$ and 
maintained in Opti-MEM (Gibco) media supplemented with 5\% heat-inactivated FBS (HyClone, Logan, UT, USA), plus $50 \mathrm{U}$ penicillin/mL and $100 \mu \mathrm{g} / \mathrm{mL}$ streptomycin (Gibco, Carlsbad, CA, USA). In order to induce neural differentiation, cells were trypsinized and cultured in DMEM-HG (Gibco) medium supplemented with $10 \mu \mathrm{M}$ retinoic acid (RA; Sigma, St. Louis, MO, USA), 10\% FBS (HyClone, Logan, UT, USA), $50 \mathrm{U}$ penicillin $/ \mathrm{mL}$ and $100 \mu \mathrm{g} / \mathrm{mL}$ streptomycin. During the RA-induced differentiation process, the NT2 cells were seeded in different plate formats (see following sections), depending on the experimental aim, and exposed to OPs (paraoxon and mipafox). OPs were freshly dissolved in cell culture media which was replaced every 2 days.

\subsection{Assessment of Cell Viability Using the MTT Assay}

To select the non-cytotoxic concentrations of paraoxon an mipafox MTT assay was performed that is widely used for evaluation of the in vitro cell viability in toxicity studies [20,28].

Cells were seeded at a density of $25 \times 10^{3}$ cells $/ \mathrm{cm}^{2}$ in uncoated 96 -well plates (BD, Franklin Lakes, NJ, USA) and cultured in RA-induced differentiation media being simultaneously exposed to different paraoxon and mipafox concentrations ranging between 0 and $300 \mu \mathrm{M}(0,0.5,1,5,10,25,40$, $70,100,150,200$ and $300 \mu \mathrm{M}$ ) for 4,10 and 15 days starting treatment on day 0 of differentiation. Cell culture medium was changed every 2 days. Cells were washed twice with phosphate buffered saline (PBS) (137 mM NaCl; $\left.2.7 \mathrm{mM} \mathrm{KCl}, 8.1 \mathrm{mM} \mathrm{Na}_{2} \mathrm{HPO}_{4}, 1.5 \mathrm{mM} \mathrm{KH} \mathrm{PO}_{4}\right)$ and $200 \mu \mathrm{L}$ of 3-(4,5-dimethylthiazol-2-yl)-2,5-diphenyltetrazolium bromide (MTT) solution (1 mg/mL) were added to each well. After $3 \mathrm{~h}$ the cells were washed with PBS and $100 \mu \mathrm{L}$ of dimethyl sulfoxide were added to each well. Plates were submitted to shaking $(50 \mathrm{rpm}, 10 \mathrm{~min})$ to ensure a complete dissolution of formazan crystals. Finally, absorbance was read at $540 \mathrm{~nm}$ in a microplate reader (Infinite ${ }^{\circledR} 200$ PRO series, Tecan Group Ltd., Männedorf, Switzerland) and the percentage of cell viability after exposure was calculated by assuming $100 \%$ of viability for the absorbance recorded in the control (non-exposed) cultures. Four independent experiments per time point were performed in each of which sixteen independent technical replicates (independent wells) were used to test each experimental condition (Figure 2).

\subsection{NTE Enzymatic Activity}

NTE activity was determined by the method of Pamies et al. [30] that is defined as phenyl valerate (PV) esterase (PVase) activity resistant to paraoxon and sensitive to mipafox. B (paraoxon-resistant) and $\mathrm{C}$ activity (resistant to both paraoxon and mipafox) are discriminated by the result from the differential sensitivities of NT2 PV esterases to nonneurotoxic paraoxon and to neurotoxic mipafox [36]. Briefly, B activity was defined and recorded as the PV hydrolyzing activity in those samples preincubated for $30 \mathrm{~min}$ at $37^{\circ} \mathrm{C}$ with $40 \mu \mathrm{M}$ paraoxon. C activity was defined and recorded as PV hydrolysing activity in the samples preincubated with $40 \mu \mathrm{M}$ paraoxon plus $250 \mu \mathrm{M}$ mipafox. In this method, NTE activity is calculated as B-C. Three independent experiments were performed in which 8 independent technical replicates were done to test each experimental condition (B and $\mathrm{C}$ activity measurements) at three time points (4, 10 and 15 days).

Cells cultured under RA-induced neurodifferentiation were seeded at density of $2 \times 10^{5} \mathrm{cells} / \mathrm{cm}^{2}$ in 96-well uncoated plates. These cells were exposed during 4, 10 and 15 days to OPs at the 
concentrations ranging between 0 and $300 \mu \mathrm{M}(0,0.5,1,5,10,25,40,70,100,150,200$ and $300 \mu \mathrm{M})$, starting the exposure at day 0 of differentiation. On each measurement day, cells were washed with PBS and incubated with $40 \mu \mathrm{M}$ paraoxon alone or in combination with $250 \mu \mathrm{M}$ mipafox in PBS for 30 min at $37^{\circ} \mathrm{C}$ to record $\mathrm{B}$ and $\mathrm{C}$ activities. The medium containing paraoxon or mipafox was removed and $100 \mu \mathrm{L}$ of $7.5 \mathrm{mM}$ PV in PBS were added to each well and incubated at $37{ }^{\circ} \mathrm{C}$ for $60 \mathrm{~min}$. The reaction was stopped by adding $100 \mu \mathrm{L}$ of $2 \%$ SDS- $0.25 \mathrm{mg} 4$-aminoantipyrine/mL in $50 \mathrm{mM}$ TRIS- 1 $\mathrm{mM}$ EDTA buffer ( $\mathrm{pH} 8.0)$. After $15 \mathrm{~min}$ at room temperature, $50 \mu \mathrm{L}$ of $1 \%(w / v)$ potassium ferricyanide (in water) were added. The released phenol was quantified by recording absorbance at 510 $\mathrm{nm}$ and by comparing to the standard curve of the phenol. NTE enzymatic activity (B-C) across three independent experiments was determined and plotted against time (Figure 3). In addition, NTE enzymatic activity was measured in parallel to microarray analysis experiments (Figure S1).

\subsection{Microarray Studies}

Maximum inhibition of NTE appeared 2 days after exposure to mipafox (Figure S1). For this reason, four days exposure to paraoxon and mipafox during RA-induced differentiation were chosen for the microarray study as this allowed two additional days for any alterations caused by NTE inhibition to translate to all complex genetic pathways. The concentrations tested were based on the following rational; $1 \mu \mathrm{M}$ paraoxon is high enough to inhibit $\mathrm{AChE}$ and other esterases not related with NTE after chronic exposures such as those employed in this study, because these enzymes are usually inhibited after $30 \mathrm{~min}$ exposure to paraoxon concentrations ranging between the $\mathrm{nM}$ and $\mu \mathrm{M}$ units [35,60-62]. Similarly, $5 \mu \mathrm{M}$ mipafox is able to cause significant inhibition of NTE, as we confirmed in experiments described in Section 4.4. It has been shown that this concentration also inhibits $\mathrm{AChE}$ since the ratio between $I C_{50}$ for inhibition of $\mathrm{AChE}$ and NTE by mipafox ranges between 1 and 10 [60].

For microarray studies the cells were cultured in petri dishes $(60 \mathrm{~mm}$, at the initial cellular density of $5 \times 10^{4}$ cells $/ \mathrm{cm}^{2}$ ) under RA-induced differentiation conditions (as described in Section 4.2.) for 4 days in the presence of $1 \mu \mathrm{M}$ paraoxon, or $5 \mu \mathrm{M}$ mipafox. After 4 days of the exposure to OPs RNA was isolated from treated cells and the control culture (non-treated). In parallel with microarray gene expression studies, the NTE enzymatic activity experiment was performed (Figure S1).

The RNeasy Plus kit (Qiagen, Germantown, MD, USA) was used. Total RNA was quantified using a ND-1000 UV-Vis Spectrophotometer (NanoDrop Technologies, Wilmington, DE, USA) and its integrity was assessed with the Agilent 2100 Bioanalyzer (Agilent, Milano, Italy) according to the manufacturer's instructions. All the RNA samples used in this study met the criteria of 260/280 ratio above 1.9 and an RNA Integrity number above 9.0. The microarray experiment was designed to perform three technical replicates for each treatment and all the samples were isolated and process at the same time. Sample-labelling, hybridization, washing and scanning steps were conducted following the manufacturer's specifications. In short, Cy3-labelled cDNA was generated from 500 ng of input total RNA using the Quick Amp Labeling Kit, One-color (Agilent). For each sample, $1.65 \mu \mathrm{g}$ of cDNA from each labelling reaction (with a specific activity above 9.0) was hybridized using the Gene expression Hybridization Kit (Agilent) to the Agilent Whole Human Genome Oligo Microarray (Agilent), which is a $4 \times 44 \mathrm{k} 60$ mer slide format where all 4 arrays represent about 41,000 unique 
genes and transcripts. After hybridization, slides were washed and then scanned in the Agilent G2565BA Microarray Scanner. The fluorescence intensities on the scanned images were extracted and pre-processed by the Agilent Feature Extraction Software (version 10.5.1.1, Agilent, Milan, Italy). Quality control and array normalization were performed in the $\mathrm{R}$ statistical environment using the Agi4 $\times 44$ PreProcess package downloaded from the Bioconductor web site. The normalization and filtering steps were based on those described in the Agi $4 \times 44$ PreProcess reference manual. In order to detect expression differences among different cell populations, a moderated $t$ test was applied. Moderated $t$ statistics were generated by the Limma Bioconductor package. Differentially expressed genes were defined as those with a $\log$ (base 2) fold change higher than 1 or lower than -1 , and a false discovery rate (Benjamini and Hochberg's method) corrected by $p$-value smaller than 0.05 [63]. All the above computations were conducted using the $\mathrm{R}$ statistics programming environment.

The expression microarray data have been deposited in the NCBI Gene Expression Omnibus and are accessible through GEO series accession number GSE38050 (NCBI. Available online: http://www.ncbi.nlm.nih.gov/geo/query/acc.cgi?acc=GSE38050 (accessed on 26 December 2013)).

The microarray results were analyzed by the DAVID (Nature. Available online: http://www.nature.com/nprot/journal/v4/n1/abs/nprot.2008.211.html, accessed on 26 December 2013) database. The analysis identified the biological functions that were altered by exposure to OPs. A right-tailed Fisher's exact test was used to calculate a $p$-value to determine the probability that each biological function assigned to that data set is due to chance alone.

\subsection{Evaluation of Cell Morphology Using Fluorescence Imaging}

RA-induced cell differentiation was performed at density of $4160 \mathrm{cells} / \mathrm{cm}^{2}$ in 96 -well uncoated plates. The cells were exposed for 13 days to either $1 \mu \mathrm{M}$ paraoxon or $5 \mu \mathrm{M}$ mipafox beginning at day 1 of differentiation. This time-point (13 days of neurodifferentiation) was chosen as it was considered to be optimal to study cell morphology (based on our own observations). Longer times of neurodifferentiation were not considered appropriate because cell processes were too dense and compromised quantification (data not shown). Cells were washed with PBS buffer and fixed for $15 \mathrm{~min}$ at room temperature with 4\% paraformaldehyde and then permeabilized for $10 \mathrm{~min}$ at room temperature (RT) with $0.1 \%$ Triton X-100 in PBS. Cells were incubated for $30 \mathrm{~min}$ at RT (room temperature) with blocking buffer (3\% FBS in PBS) on a shaker and further incubated overnight at $4{ }^{\circ} \mathrm{C}$ with $\beta$-Tubulin III (neuron-specific marker) primary antibody (Sigma T8578) diluted 1:200 in blocking buffer. Then, cells were gently washed three times with fresh medium and incubated $(1 \mathrm{~h}$ at RT in the dark and with horizontal shaking) with fluorophore conjugated with the secondary antibody Alexa 546 (Invitrogen A21123) diluted 1:500 in blocking buffer. At the end of the process cells were incubated for $10 \mathrm{~min}$ at RT with 4-6-diamidino-2-phenylindole (DAPI) diluted at 1:5000 in PBS for staining the cell nuclei. DAPI was used for nucleus staining (a fluorescent stain that binds strongly to A-T rich regions in DNA). Cell morphology was analyzed using the imaging platform Cellomics ArrayScan vTi (Thermo Scientific Cellomics ${ }^{\circledR}$, Pittsburgh, PA, USA). The software (Neuronal Profiling version 4, BioApplication from Cellomics Scan Software (Thermo Scientific Cellomics ${ }^{\circledR}$, Pittsburgh, PA, USA)) was set to measure number of branch points, neurite length and percentage of differentiated neurons per total neuron count. The threshold for considering cells as differentiated 
neurons was more than 3 neurites or a neurite of a total length longer than $6.5 \mu \mathrm{m}$ associated to a single cell body.

\section{Conclusions}

The obtained results suggest that the NT2 cell line is a suitable in vitro model for studying the effect of OPs on the initial stages of RA-induced differentiation of pluripotent stem cells towards neural committed progenitor cells followed up by the early processes of neuronal-like cell differentiation.

Paraoxon and mipafox have been used as examples to study non-neuropathic and neuropathic OPs, respectively. Paraoxon alters the initial in vitro differentiation process of neural progenitor cells, probably due to chromosome packaging and chromatin organization. Further studies are needed to clarify whether these effects might cause some of the neurodevelopmental toxic effects attributed to OPs. Nevertheless, we previously estimated that in vivo paraoxon exposures causing severe cholinesterase syndrome would yield systemic concentrations of $0.1-0.3 \mu \mathrm{M}$ [64]. Therefore, $1 \mu \mathrm{M}$, the concentration at which the in vitro effects reported in this work were observed, would be comparable with clinical cholinergic symptoms. Thus, low risk during developmental stages is expected, which is consistent with data showing alteration in the gene expression profile of D3 mouse embryonic stem cells exposed to chlorpyrifos at concentrations which also cause moderate AChE inhibition [17]. On the other hand, $5 \mu \mathrm{M}$ of mipafox was able to reduce NTE enzymatic activity. No modifications were observed in mRNA levels, indicating that NTE enzymatic activity is probably not involved in genetic signaling. Our insights into the effects of paraoxon exposure during early windows of cell differentiation call for more data to complete risk characterization since we have studied a single concentration $(1 \mu \mathrm{M})$ and further concentrations would provide information on where the threshold for the described effects lies.

\section{Acknowledgments}

The European Commission, Joint Research Centre (Ispra, I) supported the visit of David Pamies to the Institute for Health and Consumer Protection. Marco Fabbri is a student of the $\mathrm{PhD}$ program in Biotechnology, School of Biological and Medical Sciences, University of Insubria.

\section{Conflicts of Interest}

The authors declare no conflicts of interest.

\section{References}

1. Business Analytic Center. Insecticides: European Union Market Outlook 2011 and Forecast till 2016; PRNewswire: New York, NY, USA, 2011.

2. Bronstein, A.C.; Spyker, D.A.; Cantilena, L.R., Jr.; Green, J.L.; Rumack, B.H.; Dart, R.C. 2010 Annual Report of the American Association of Poison Control Centers' National Poison Data System (NPDS): 28th Annual Report. Clin. Toxicol. 2011, 49, 910-941.

3. Bjørling-Poulsen, M.; Andersen, H.R.; Grandjean, P. Potential developmental neurotoxicity of pesticides used in Europe. Environ. Health 2008, 7, 50. 
4. Grandjean, P.; Landrigan, P.J. Developmental neurotoxicity of industrial chemicals. Lancet 2006, $368,2167-2178$.

5. Hogberg, H.T.; Kinsner-Ovaskainen, A.; Hartung, T.; Coecke, S.; Bal-Price, A.K. Gene expression as a sensitive endpoint to evaluate cell differentiation and maturation of the developing central nervous system in primary cultures of rat cerebellar granule cells (CGCs) exposed to pesticides. Toxicol. Appl. Pharmacol. 2009, 235, 268-286.

6. Rohlman, D.S.; Arcury, T.A.; Quandt, S.A.; Lasarev, M., Rothlein, J.; Travers, R.; Tamulinas, A.; Scherer, J.; Early, J.; Marín, A.; et al. Neurobehavioral performance in preschool children from agricultural and non-agricultural communities in Oregon and North Carolina. Neurotoxicology 2005, 26, 589-598.

7. Grandjean, P.; Harari, R.; Barr, D.B.; Debes, F. Pesticide exposure and stunting as independent predictors of neurobehavioral deficits in Ecuadorian school children. Pediatrics 2006, 117, e546-e556.

8. World Health Organization. Organophosphorus Insecticides: A general introduction. World Health Organization, Environmental Health Criteria 63. 1986. Available online: http://www.inchem.org/documents/ehc/ehc/ehc63.htm (accessed on 26 December 2013).

9. Glynn, P. NTE: One target protein for different toxic syndromes with distinct mechanisms? Bioessays 2003, 25, 742-745.

10. Roldán-Tapia, L.; Nieto-Escámez, F.A.; del Águila, E.M.; Laynez, F.; Parrón, T.; Sánchez-Santed, F. Neuropsychological sequelae from acute poisoning and long-term exposure to carbamate and organophosphate pesticides. Neurotoxicol. Teratol. 2006, 28, 694-703.

11. Mackenzie Ross, S.J.; Brewin, C.R.; Curran, H.V.; Furlong, C.E.; Abraham-Smith, K.M.; Harrison, V. Neuropsychological and psychiatric functioning in sheep farmers exposed to low levels of organophosphate pesticides. Neurotoxicol. Teratol. 2010, 32, 452-459.

12. Parrón, T.; Requena, M.; Hernández, A.F.; Alarcón, R. Association between environmental exposure to pesticides and neurodegenerative diseases. Toxicol. Appl. Pharmacol. 2011, 256, 379-385.

13. Gupta, R.C.: Malik, J.K.; Milatovic, D. Organophosphate and Carbamate Pesticides. In Reproductive and Developmental Toxicology; Gupta, R.C., Eds.; Elsevier: London, UK, 2011; pp. 471-486.

14. Flaskos, J. The developmental neurotoxicity of organophosphorus insecticides: A direct role for the oxon metabolites. Toxicol. Lett. 2012, 209, 86-93.

15. Lauder, J.M.; Schambra, U.B. Morphogenetic roles of acetylcholine. Environ. Health Perspect. 1999, 107, 65-69.

16. Johnson, F.O.; Chambers, J.E.; Nail, C.A.; Givaruangsawat, S.; Carr, R.L. Developmental chlorpyrifos and methyl parathion exposure alters radial-arm maze performance in juvenile and adult rats. Toxicol. Sci. 2009, 109, 132-142.

17. Moreira, E.G.; Yu, X.; Robinson, J.F.; Griffith, W.; Hong, S.W.; Beyer, R.P.; Bammler, T.K.; Faustman, E.M. Toxicogenomic profiling in maternal and fetal rodent brains following gestational exposure to chlorpyrifos. Toxicol. Appl. Pharmacol. 2010, 245, 310-325. 
18. Estevan, C.; Vilanova, E.; Sogorb, M.A. Chlorpyrifos and its metabolites alter gene expression at non-cytotoxic concentrations in D3 mouse embryonic stem cells under in vitro differentiation: Considerations for embryotoxic risk assessment. Toxicol. Lett. 2012, 217, 14-22.

19. Guillette, E.A.; Meza, M.M.; Aquilar, M.G.; Soto, A.D.; Garcia, I.E. An anthropological approach to the evaluation of preschool children exposed to pesticides in Mexico. Environ. Health Perspect. 1998, 106, 347-353.

20. Hogberg, H.T.; Sobanski, T.; Novellino, A.; Whelan, M.; Weiss, D.G.; Bal-Price, A.K. Application of micro-electrode arrays (MEAs) as an emerging technology for developmental neurotoxicity: Evaluation of domoic acid-induced effects in primary cultures of rat cortical neurons. Neurotoxicology 2011, 32, 158-168.

21. Bal-Price, A.K.; Hogberg, H.T.; Buzanska, L.; Lenas, P.; van Vliet, E.; Hartung, T. In vitro developmental neurotoxicity (DNT) testing: Relevant models and endpoints. Neurotoxicology 2009, 31, 545-554.

22. Coyle, D.E.; Li, J.; Baccei, M. Regional differentiation of retinoic acid-induced human pluripotent embryonic carcinoma stem cell neurons. PLoS One 2011, 6, e16174.

23. Andrews, P.W. From teratocarcinomas to embryonic stem cells. Philos. Trans. R. Soc. Lond. B 2002, 357, 405-417.

24. Tegenge, M.A.; Roloff, F.M.; Bicker, G. Rapid differentiation of human embryonal carcinoma stem cells (NT2) into neurons for neurite outgrowth analysis. Cell. Mol. Neurobiol. 2011, 31, 635-643.

25. Stummann, T.C.; Hareng, L.; Bremer, S. Hazard assessment of methylmercury toxicity to neuronal induction in embryogenesis using human embryonic stem cells. Toxicology 2009, 257, $117-126$.

26. Buzanska, L.; Sypecka, J.; Nerini-Molteni, S.; Compagnoni, A.; Hogberg, H.T.; del Torchio, R.; Domanska-Janik, K.; Zimmer, J.; Coecke, S. A human stem cell-based model for identifying adverse effects of organic and inorganic chemicals on the developing nervous system. Stem Cells 2009, 27, 2591-2601.

27. Slotkin, T.; Seidler, F. Transcriptional profiles reveal similarities and differences in the effects of developmental neurotoxicants on differentiation into neurotransmitter phenotypes in PC12 cells. Brain Res. Bull. 2009, 78, 211-22530.

28. Camon, E.; Barrell, D.; Lee, V.; Dimmer, E.; Apweiler, R. The Gene Ontology Annotation (GOA) Database-An integrated resource of GO annotations to the UniProt Knowledgebase. In Silico Biol. 2004, 4, 5-6.

29. Crumpton, T.L.; Seidler, F.J.; Slotkin, T.A. Developmental neurotoxicity of chlorpyrifos in vivo and in vitro: Effects on nuclear transcription factors involved in cell replication and differentiation. Brain. Res. 2000, 857, 87-98.

30. Ehrich, M.; Intropido, L.; Costa, L.G. Interaction of organophosphorus compounds with muscarinic receptors in SH-SY5Y human neuroblastoma cells. J. Toxicol. Environ. Health 1994, 43, 51-63.

31. Garcia, S.J.; Seidler, F.J.; Crumpton, T.L.; Slotkin, T.A. Does the developmental neurotoxicity of chlorpyrifos involve glial targets? Macromolecule synthesis, adenylyl cyclase signaling, nuclear transcription factors, and formation of reactive oxygen in C6 glioma cells. Brain Res. 2001, 891, $54-68$. 
32. Pamies, D.; Vilanova, E.; Sogorb, M.A. Functional pathways altered after silencing Pnpla6 (the codifying gene of Neuropathy Target Esterase) in mouse embryonic stem cells under differentiation. In Vitro Cell. Dev. Biol. Anim. 2013, doi:10.1007/s11626-013-9691-4.

33. Moser, M.; Li, Y.; Vaupel, K.; Kretzschmar, D.; Kluge, R.; Glynn, P.; Buettner, R. Placental failure and impaired vasculogenesis result in embryonic lethality for neuropathy target esterase-deficient mice. Mol. Cell. Biol. 2004, 24, 1667-1679.

34. Lotti, M.; Moretto, A. Organophosphate-induced delayed polyneuropathy. Toxicol. Rev. 2005, 24, $37-49$.

35. Estévez, J.; Mangas, I.; Sogorb, M.Á.; Vilanova, E. Interactions of neuropathy inducers and potentiators/promoters with soluble esterases. Chem. Biol. Interact. 2013, 203, 245-250.

36. Johnson, M.K. The delayed neurotoxic effect of some organophosphorus compounds. Identification of the phosphorylation site as an esterase. Biochem. J. 1969, 114, 711-717.

37. Pallocca, G.; Fabbri, M.; Sacco, M.G.; Gribaldo, L.; Pamies, D.; Laurenza, I.; Bal-Price, A. miRNA expression profiling in a human stem cell-based model as a tool for developmental neurotoxicity testing. Cell Biol. Toxicol. 2013, 29, 239-257.

38. Hong, M.S.; Hong, S.J.; Barhoumi, R.; Burghardt, R.C.; Donnelly, K.C.; Wild, J.R.; Venkatraj, V.; Tiffany-Castiglioni, E. Neurotoxicity induced in differentiated SK-N-SH-SY5Y human neuroblastoma cells by organophosphorus compounds. Toxicol. Appl. Pharmacol. 2003, 186, $110-118$.

39. Sachana, M.; Flaskos, J.M.; Alexaki, E.M. Hargreaves, A.J. Inhibition of neurite outgrowth in N2a cells by leptophos and carbaryl: effects on neurofilament heavy chain, GAP-43 and HSP-70. Toxicol. In Vitro 2003, 17, 115-120.

40. Sachana, M.; Flaskos, J.; Sidiropoulou, E.; Yavari, C.A.; Hargreaves, A.J. Inhibition of extension outgrowth in differentiating rat C6 glioma cells by chlorpyrifos and chlorpyrifos oxon: Effects on microtubule proteins. Toxicol. In Vitro 2008, 22, 1387-1391.

41. Howard, A.S.; Bucelli, R.; Jett, D.A.; Bruun, D.M.; Yang, D.; Lein, P.J. Chlorpyrifos exerts opposing effects on axonal and dendritic growth in primary neuronal cultures. Toxicol. Appl. Pharmacol. 2005, 207, 112-124.

42. Massicotte, C.; Jortner, B.S.; Ehrich, M. Morphological effects of neuropathy-inducing organophosphorus compounds in primary dorsal root ganglia cell cultures. Neurotoxicology 2003, 24, 787-796.

43. Li, W.; Casida, J.E. Organophosphorus neuropathy target esterase inhibitors selectively block outgrowth of neurite-like and cell processes in cultured cells. Toxicol. Lett. 1998, 98, 139-146.

44. Henschler, D.; Schmuck, G.; van Aerssen, M.; Schiffmann, D. The inhibitory effect of neuropathic organophosphate esters on neurite outgrowth in cell cultures: A basisfor screening for delayed neurotoxicity. Toxicol. In Vitro 1992, 6, 327-235.

45. Li, Z.; Szurek, P.F.; Jiang, C.; Pao, A.; Bundy, B.; Le, W.D.; Bradley, A.; Yu, Y.E. Neuronal differentiation of NTE-deficient embryonic stem cells. Biochem. Biophys. Res. Commun. 2005, 330, 1103-1109.

46. Slotkin, T.A.; Levin, E.D.; Seidler, F.J. Developmental neurotoxicity of parathion: Progressive effects on serotonergic systems in adolescence and adulthood. Neurotoxicol. Teratol. 2009, 31, $11-17$. 
47. Laurenza, I.; Pallocca, G.; Mennecozzi, M.; Scelfo, B.; Pamies, D.; Bal-Price, A. A human pluripotent carcinoma stem cell-based model for in vitro developmental neurotoxicity testing: Effects of methylmercury, lead and aluminum evaluated by gene expression studies. Int. J. Dev. Neurosci. 2013, doi:10.1016/j.ijdevneu.2013.03.002.

48. Pleasure, S.J.; Page, C.; Lee, V.M. Pure, postmitotic, polarized human neurons derived from NTera 2 cells provide a system for expressing exogenous proteins in terminally differentiated neurons. J. Neurosci. 1992, 12, 1802-1815.

49. Li, B.; Zhou, J.; Liu, P.; Hu, J.; Jin, H.; Shimono, Y.; Takahashi, M.; Xu, G. Polycomb protein Cbx4 promotes SUMO modification of de novo DNA methyltransferase Dnmt3a. Biochem. J. 2007, 405, 369-378.

50. Marzluff, W.F.; Gongidi, P.; Woods, K.R.; Jin, J.; Maltais, L.J. The human and mouse replication-dependent histone genes. Genomics 2002, 80, 487-498.

51. Camargo, F.D.; Gokhale, S.; Johnnidis, J.B.; Fu, D.; Bell, G.W.; Jaenisch, R.; Brummelkamp, T.R. YAP1 increases organ size and expands undifferentiated progenitor cells. Curr. Biol. 2007, 17, 2054-2060. Erratum in: Curr. Biol. 2007, 17, 2094.

52. Singh, S.; Kumar, V.; Thakur, S.; Banerjee, B.D.; Chandna, S.; Rautela, R.S.; Grover, S.S.; Rawat, D.S.; Pasha, S.T.; Jain, S.K.; et al. DNA damage and cholinesterase activity in occupational workers exposed to pesticides. Environ. Toxicol. Pharmacol. 2011, 31, 278-285.

53. Singh, S.; Kumar, V.; Vashisht, K.; Singh, P.; Banerjee, B.D.; Rautela, R.S.; Grover, S.S.; Rawat, D.S.; Pasha, S.T.; Jain, S.K.; et al. Role of genetic polymorphisms of CYP1A1, CYP3A5, CYP2C9, CYP2D6, and PON1 in the modulation of DNA damage in workers occupationally exposed to organophosphate pesticides. Toxicol. Appl. Pharmacol. 2011, 257, 84-92.

54. Singh, S.; Kumar, V.; Thakur, S.; Banerjee, B.D.; Rautela, R.S.; Grover, S.S.; Rawat, D.S.; Pasha, S.T.; Jain, S.K.; Ichhpujani, R.L.; et al. Paraoxonase-1 genetic polymorphisms and susceptibility to DNA damage in workers occupationally exposed to organophosphate pesticides. Toxicol. Appl. Pharmacol. 2011, 252, 130-137.

55. Hébert, J.M.; Lin, M.; Partanen, J.; Rossant, J.; McConnell, S.K. FGF signaling through FGFR1 is required for olfactory bulb morphogenesis. Development 2003, 130, 1101-1111.

56. Zhang, H.; Deo, M.; Thompson, R.C.; Uhler, M.D.; Turner, D.L. Negative regulation of Yap during neuronal differentiation. Dev. Biol. 2012, 361, 103-115.

57. Teixidó, E.; Piqué, E.; Gómez-Catalán, J.; Llobet, J.M. Assessment of developmental delay in the zebrafish embryo teratogenicity assay. Toxicol. In Vitro 2013, 27, 469-478.

58. Islas-González, K.; González-Horta, C.; Sánchez-Ramírez, B.; Reyes-Aragón, E.; Levario-Carrillo, M. In vitro assessment of the genotoxicity of ethyl paraoxon in newborns and adults. Hum. Exp. Toxicol. 2005, 24, 319-324.

59. Hreljac, I.; Zajc, I.; Lah, T.; Filipic, M. Effects of model organophosphorous pesticides on DNA damage and proliferation of HepG2 cells. Environ. Mol. Mutagen. 2008, 49, 360-367.

60. Sogorb, M.A.; González-González, I.; Pamies, D.; Vilanova, E. An alternative in vitro method for detecting neuropathic compounds based on acetylcholinesterase inhibition and on inhibition and aging of neuropathy target esterase (NTE). Toxicol. In Vitro 2010, 24, 942-952.

61. Mangas, I.; Vilanova, E.; Estévez, J. NTE and non-NTE esterases in brain membrane: Kinetic characterization with organophosphates. Toxicology 2012, 297, 17-25. 
62. Mangas, I.; Vilanova, E.; Estévez, J. Kinetics of the inhibitory interaction of organophosphorus neuropathy inducers and non-inducers in soluble esterases in the avian nervous system. Toxicol. Appl. Pharmacol. 2011, 256, 360-368.

63. Smyth, G.K. Linear models and empirical bayes methods for assessing differential expression in microarray experiments. Stat. Appl. Genet. Mol. Biol. 2004, 3, 30.

64. Sogorb, M.A.; García-Argüelles, S.; Carrera, V.; Vilanova, E. Serum albumin is as efficient as paraxonase in the detoxication of paraoxon at toxicologically relevant concentrations. Chem. Res. Toxicol. 2008, 21, 1524-1529.

(C) 2014 by the authors; licensee MDPI, Basel, Switzerland. This article is an open access article distributed under the terms and conditions of the Creative Commons Attribution license (http://creativecommons.org/licenses/by/3.0/). 